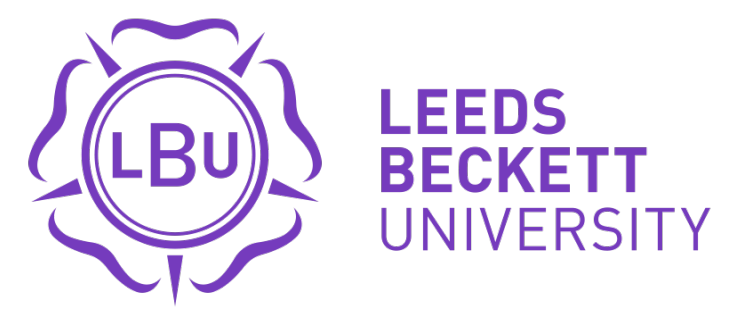

Citation:

Duncan, MJ and Al-Hazzaa, HM and Al-Nakeeb, $\mathrm{Y}$ and Al-Sobayel, $\mathrm{HI}$ and Abahussain, NA and Musaiger, AO and Lyons, M and Collins, P and Nevill, A (2014) Anthropometric and Lifestyle Characteristics of Active and Inactive Saudi and British Adolescents. American Journal of Human Biology, 26 (5). 635 - 642. ISSN 1520-6300 DOI: https://doi.org/10.1002/ajhb.22574

Link to Leeds Beckett Repository record:

https://eprints.leedsbeckett.ac.uk/id/eprint/1611/

Document Version:

Article (Accepted Version)

The aim of the Leeds Beckett Repository is to provide open access to our research, as required by funder policies and permitted by publishers and copyright law.

The Leeds Beckett repository holds a wide range of publications, each of which has been checked for copyright and the relevant embargo period has been applied by the Research Services team.

We operate on a standard take-down policy. If you are the author or publisher of an output and you would like it removed from the repository, please contact us and we will investigate on a case-by-case basis.

Each thesis in the repository has been cleared where necessary by the author for third party copyright. If you would like a thesis to be removed from the repository or believe there is an issue with copyright, please contact us on openaccess@leedsbeckett.ac.uk and we will investigate on a case-by-case basis. 


\section{Anthropometric and lifestyle characteristics of active and inactive Saudi and British adolescents}

Duncan, M.J. , Al-hazzaa, H.M. , Al-Nakeeb, Y. , Al-Sobayel, H.I. , Abahussain, N.A. , Musaiger, A.O. , Lyons, M. , Collins, P. and Nevill, A.

Author post-print (accepted) deposited in CURVE June 2015

Original citation \& hyperlink:

Duncan, M.J. , Al-hazzaa, H.M. , Al-Nakeeb, Y. , Al-Sobayel, H.I. , Abahussain, N.A. , Musaiger, A.O. , Lyons, M. , Collins, P. and Nevill, A. (2014) Anthropometric and lifestyle characteristics of active and inactive Saudi and British adolescents. American Journal of Human Biology, volume 26 (5): 635-642.

http://dx.doi.org/10.1002/ajhb.22574

Publisher statement: This is the peer reviewed version of the following article: American Journal of Human Biology, 26 (5), pp. 635-642, which has been published in final form at http://dx.doi.org/10.1002/ajhb.22574. This article may be used for non-commercial purposes in accordance With Wiley Terms and Conditions for self-archiving.

Copyright $(C$ and Moral Rights are retained by the author(s) and/ or other copyright owners. A copy can be downloaded for personal non-commercial research or study, without prior permission or charge. This item cannot be reproduced or quoted extensively from without first obtaining permission in writing from the copyright holder(s). The content must not be changed in any way or sold commercially in any format or medium without the formal permission of the copyright holders.

This document is the author's post-print version, incorporating any revisions agreed during the peer-review process. Some differences between the published version and this version may remain and you are advised to consult the published version if you wish to cite from it. 


\title{
Anthropometric and Lifestyle Characteristics of Active and Inactive Saudi and British Adolescents
}

\author{
Michael J Duncan ${ }^{1}$, Hazzaa M Al-Hazzaa ${ }^{1,2,8}$, Yahya Al-Nakeeb ${ }^{3,8}$, Hana I Al-Sobayel \\ ${ }^{4}$, Nada A Abahussain ${ }^{5}$, Abdulrahman O Musaiger ${ }^{6}$, Mark Lyons ${ }^{7}$, Peter Collins ${ }^{8}$, \\ Alan Nevill ${ }^{9}$
}

${ }^{1}$ Faculty of Health and Life Sciences, Coventry University, Coventry, UK (aa8396@coventry.ac.uk)

${ }^{2}$ Director of Pediatric Exercise Physiology Research Laboratory, College of Education, and member of Scientific Boards, Obesity Research Chair, King Saud University, Riyadh, Saudi Arabia (alhazzaa@ksu.edu.sa)

${ }^{3}$ College of Education, Qatar University, Qatar (alnakeeb@qu.edu.qa)

${ }^{4}$ Department of Rehabilitation Sciences, College of Applied Medical Sciences, King Saud University, Riyadh, Saudi Arabia (hsobayel@ksu.edu.sa)

${ }^{5}$ Director of School Health, Ministry of Education, Eastern Province, Saudi Arabia (n_abahussain@hotmail.com)

${ }^{6}$ Director of Arab Center for Nutrition, Manama, Bahrain (amusaiger@gmail.com)

${ }^{7}$ Department of Physical Education and Sport Sciences, University of Limerick, Ireland (mark.lyons@ul.ie)

${ }^{8}$ School of Human Sciences, Newman University College, Birmingham, UK (p.collins@newman.ac.uk)

${ }^{9}$ School of Performing Arts and Leisure, University of Wolverhampton, Walsall, UK (a.m.nevill@wlv.ac.uk)

Running Title: Anthropometric and Lifestyle Characteristics 


\section{Abstract}

Objectives: To compare the anthropometric and lifestyle characteristics of active and inactive adolescents in Saudi Arabia and Britain.

Methods: A school-based cross-sectional study was conducted at four cities in Saudi Arabia (Riyadh and Al-Khobar; $\mathrm{N}=1,648$ ) and Britain (Birmingham and Coventry; $\mathrm{N}=$ 1,158). The participants (14-18 year-olds) were randomly selected using a multistage stratified cluster sampling. Measurements included anthropometric (BMI, Waist circumference, Waist to height ratio), screen time, validated physical activity (PA) questionnaire and dietary habits

Results: British males were lighter ( $p=.04,64.4$ vs $68.2 \mathrm{~kg}$ ), and had lower values for WC $(p=.003,77.1$ vs $78.7 \mathrm{~cm})$ than Saudi males. Males $(p=.0001)$ were significantly more active than females but the difference between inactive Saudi and British females was greater than that between inactive Saudi and British males. Being female was significantly $(p<0.001)$ associated with lower activity levels in both the Saudi and British adolescents. Having lower frequency of fruit intake was significantly $(p<0.001)$ was associated with lower activity levels, whereas increased frequency of consumption of French fries/potato chips was significantly $(p=0.008)$ associated with increased activity levels in Saudi adolescents. Among British adolescents, lower frequency of breakfast was $(p=0.045)$ associated with lower activity levels, increased frequency of consumption of sweetened beverages was significantly $(p=0.005)$ associated with higher activity levels. Higher energy drinks intake frequency was significantly $(p=0.007)$ associated with higher activity levels. 
Conclusions: The present study identifies cross-cultural differences and similarities in lifestyle habits in adolescents from Britain and Saudi Arabia. Activity status (active vs inactive) appears to play an important role in other lifestyle related behaviours, with active adolescent more likely to engage in healthy dietary behavior than their inactive peers, irrespective of country of origin.

Keywords: adolescents; British; culture; dietary habits; lifestyle factors; physical activity; Saudi

\section{Introduction}

The importance of developing healthy lifestyle habits in children and adolescents is indisputable (World Health Organization, 2004). A range of prior studies have documented how lifestyle factors including lack of physical activity, increased sedentary behavior and poor eating/dietary habits contribute to increased CVD morbidity and mortality in adults (Riddoch et al., 2005) and that these habits and subsequent disease processes develop in childhood (Wedderkopp et al., 2003).

Adolescence is a particularly important developmental period related to this issue as dietary habits, physical activity and weight status all track from adolescence into adulthood (Telama, 2009; Rasmussen et al., 2006). It is also a period where sedentary behavior increases (Mitchell et al., 2012), physical activity declines (Troiano et al., 2008) with an increased nutritional demand due to the rapid physical growth in adolescence. The three main factors of sedentary behavior, physical activity and eating habits are all 
independent contributors to the development of chronic disease including overweight and obesity (Ekelund et al., 2006, Sardinha et al., 2008) As a consequence, the adolescent developmental period provides an important opportunity for the establishment of health enhancing behaviours. It is also a period worthy of scrutiny in order to effectively target interventions and policy recommendations.

In the context of a globalised society and one where lifestyle behaviours are the leading cause of preventable chronic disease worldwide, understanding cross-cultural differences in lifestyle behaviours may be particularly useful in understanding how different environments and cultures may influence lifestyle behaviours. Such data is also useful in order to clarify conflicting observations derived from specific populations (Beardsley and Pendersen, 1997), particularly as PA opportunities (Nilsson et al., 2009) and eating behaviours (Sluyter et al., 2010) differ by country. It has previously been recognized that many complex factors including personal, cultural, social and ethnicity (Rogers, 1997; Duncan et al 2012) form the health related behaviours and attitudes of young people. Comparative research is therefore useful in such circumstances to help understand how diverse cultural, social and environmental factors might impact on health related behaviours.

This study therefore focuses on two diverse geographical locations, Saudi Arabia and the United Kingdom. Overweight and obesity are at epidemic proportions in both countries (Al-Hazzaa, 2007; Shaw et al., 2007) and lack of physical activity, increased sedentary behavior and poor dietary habits have been posited as antecedents to this situation in both the UK and Saudi. However, the environmental, social and cultural circumstances differ between the two countries. In Saudi Arabia, there has been a nutritional transition to a westernized, calorie-dense diet (Al-Hazzaa et al., 2011c) leading 
to increased overweight and obesity and in both countries healthy dietary habits are below recommended levels (Vereecken et al., 2005). There are also contrasting climatic and built environments between the UK and Saudi Arabia which may influence physical activity and sedentary behaviours in different ways between the countries (Al-Hazzaa et al., 2013a). Furthermore, cultural differences between the UK and Saudi Arabia have largely resulted in Saudi females having fewer opportunities for PA and increased opportunity for screen based sedentary behaviours compared to Saudi males and to their British peers (Al-Hazzaa et al., 2013a). This study therefore sought to build on prior research in the area by comparing the anthropometric and lifestyle characteristics of active and inactive adolescents in Saudi Arabia and Britain. The study hypothesized that there would be differences in lifestyle (physical activity and dietary habits) and anthropometric characteristics of inactive and active youth and that these differences would also be influenced by country of residence.

\section{Methods}

\section{Participants}

Following institutional ethics approval and informed consent, a total of 2806 adolescents aged 14-18 years participated in the present study drawn from four major cities in Saudi Arabia and Britain with 1648 participants being drawn from Saudi Arabia and 1158 from Britain. Saudi Arabian samples came from Riyadh, the capital city of Saudi Arabia and located centrally within the country and from Al-Khobar, a modern city located in the eastern coast of Saudi Arabia. British participants were drawn from the cities of Birmingham and Coventry; both are from the central part of England with Birmingham being the second largest city in the United Kingdom. Response rates across countries were not significantly different. 
A multistage stratified random-sampling technique was employed to select the students from the secondary schools in the participating four cities. Unified written instructions were applied to the data collection in both countries with students who were free form any major health problem being included in the study. Data were derived from the Arab Teens Lifestyle Study (ATLS) conducted in Saudi Arabia (Al-Hazzaa et al., 2011a; Al-Hazzaa et al., 2011c) and similar research that was conducted in Britain (AlNakeeb et al., 2012). ATLS is a school based, cross-sectional multicenter lifestyle project and detailed description of ATLS can be found elsewhere (Al-Hazzaa et al., 2011a; AlHazzaa et al., 2011c).

\section{Anthropometric measurements}

All measurements were performed in the morning by a trained researcher according to written standardized procedures. Body weight was measured to the nearest $100 \mathrm{~g}$ using calibrated portable scales (Seca Ltd., Hamburg, Germany) while the participant wearing minimal clothing and without shoes. Height was measured to the nearest centimeter using a calibrated measuring rod while the subject was in a full standing position without shoes. Body mass index (BMI) was calculated as $\mathrm{kg} / \mathrm{m}^{2}$ with participant weight status subsequently classified using the International Obesity Task Force (IOTF) age- and sex-specific BMI cutoff reference standards (Cole et al., 2000) for adolescents between the ages of 14-17 years. For participants aged 18 years, we used the adult cut-off points of $25-29.9 \mathrm{~kg} / \mathrm{m}^{2}$ to define overweight and $30 \mathrm{~kg} / \mathrm{m}^{2}$ and higher for obesity. In addition, waist circumference was assessed midway between the rib cage and the superior border of the iliac crest using an anthropometric tape measure with participants standing and at the end of gentle expiration. Waist circumference (WC: $\mathrm{cm}$ ) 
and waist to height ratio $(\mathrm{WHtR})$ were then used as measures of weight status in addition to BMI.

\section{Assessment of lifestyle factors}

A validated self-report questionnaire was used to assess physical activity levels, sedentary behaviors and dietary habits of the adolescents. In all cases the questionnaire was completed in a school classroom under the supervision of their teachers and in front of at least one of the research assistants. The instrument has been previously evaluated for reproducibility and validity and was found to have high reliability (Al-Hazzaa and AlAhmadi, 2003) and an acceptable validity (Al-Hazzaa et al., 2011b). The questionnaire was translated, making every effort to have the questionnaire items as conceptually and functionally equivalent, and back translated from Arabic to English by one of the authors (YA) who is bilingual. The translation was reviewed and confirmed by another bilingual author of this paper (HMA) and procedures were conducted according to acceptable methods. Pilot data with a sample of British adolescents (aged 15-18 years) confirmed the appropriateness and the full understanding of questionnaire content in British adolescents. No modifications were required, thus construct validity was assumed.

The physical-activity part of the questionnaire intended to collect information on frequency, duration and intensity of a variety of light-, moderate- and vigorous-intensity physical activities during a typical week and across different activity domains (transport, household, fitness and sports activities). Metabolic equivalent (MET) values were attributed to the physical activities based on the compendium of physical activity (Ainsworth et al., 2011) and the compendium of physical activity for youth (Ridley et al., 2008). Physical activity levels were then classified into two categories (active or inactive) 
based on a cut-off value for total METs-min/weekof below or $\geq 1680$ MET-min/week.,. These cut-offs were employed as a score of $1680 \mathrm{METs}-\mathrm{min} /$ week is equivalent to $60 \mathrm{~min}$ of moderate-intensity daily physical activity (60 $\min \times 7$ days $\times 4$ METs $=1680$ METs$\mathrm{min} /$ week), and a score of $2520 \mathrm{METs}-\mathrm{min} /$ week is equivalent to $60 \mathrm{~min}$ of moderate-to vigorous- intensity daily physical activity (60 $\min \times 7$ days $\times 6$ METs $=2520$ METs$\min /$ week).

The dietary habit section of the questionnaire covered healthy and unhealthy dietary behaviors and asked how many times in a typical week the participants consumed breakfast, vegetables (cooked and uncooked), fruit, milk and dairy products, sugarsweetened drinks including soft beverages, donuts and cakes, candy and chocolate, energy drinks and fast foods. Possible responses ranged from zero intake (never) to a maximum intake of 7 days per week (every day). Participants were then classified into two categories based on the frequency of their intake for each respective food (4+ days/week, < 4 days/week). Sedentary behaviors were then assessed by asking how much time in a typical day was spent viewing TV, playing video games, and computer and internet use. To classify total screen time, the American Academy of Pediatrics (AAP) guidelines of a maximum of 2 hours per day (American Academy of Pediatrics, 2001) were employed.

\section{Statistical analysis}

Data in each participating city were checked and entered into a computer using standardized entry codes written on an SPSS (SPSS, Inc, Chicago, IL) data file. The current analysis included age range between 14 and 18 years. Data were then analyzed using SPSS, version 20. There was no evidence of sample clustering, as intra-class 
correlation coefficients were very low and were nonsignificant ( $p$ value averaged 0.481 in Saudi data and 0.488 in British data). Descriptive statistics were presented as means, standard deviations and proportions. Participants were also classified as active or inactive based on a cut-off value of 1680 METs-min/week of activity energy expenditure. The value of 1680 METs-min/week is equivalent to $60 \mathrm{~min}$ of moderate-to vigorous- intensity daily physical activity. Differences in anthropometric characteristics between countries relative to gender and activity level were tested using three-way MANCOVA controlling for the effect of age. Categories of dietary frequency between active and inactive Saudi and British adolescents were cross-tabulated with Chi-square tests. Three-way MANCOVA tests, controlling for age were used to test the differences in dietary habits relative to gender, country and activity level. Finally, logistic regression analysis, adjusted for age, gender and overweight/obesity status was used to test the associations of dietary habits with activity category (active versus inactive). The level of significance was set at 0.05 or less.

\section{Results}

Anthropometric characteristics of the participants stratified by gender, country and activity status are presented in Table 1. Adolescents from Saudi were significantly older than British adolescents $(p=0.008)$. There were significant gender by country interactions for weight $(p=0.04)$, height $(p=0.007)$, WC $(p=0.003)$ and WHtR $(p$ $=0.025)$. British males were lighter and had lower values for WC than Saudi males but these differences were not evident for females. British males and females were also taller than their Saudi peers. British males had lower WHtR compared to Saudi males, with no difference in WHtR between British and Saudi females. There was also a gender by 
activity interaction for BMI $(p=0.014)$ where active males and females had lower BMI values than inactive males and females respectively. However, the difference in BMI was lower between inactive Saudi and British females compared to the other groups. with this pattern being reversed for females. In regard to activity energy expenditure in METsmin/week for the Saudi and British adolescents, the significant gender $x$ activity interaction $(p=0.0001)$ indicated that males were significantly more active than females but that the difference between inactive females was greater than that between inactive males. In addition, the significant main effect for country $(p=0.0001)$ indicated higher activity energy expenditure in British adolescents compared to their Saudi peers. Overall, $64 \%$ of Saudis were considered inactive, whereas this figure was $25.5 \%$ among British adolescents.

XXXXTable 1 Here XXXX

The differences in dietary habits between active and inactive Saudi and British adolescents relative to gender are presented in Table 2. Cross tabulation results showed that there were no significant differences between active or inactive Saudi and British adolescents in breakfast and fruit intakes $(p>0.05)$. Compared with active British males, active Saudi males had higher intakes of vegetables $(p=0.001)$, milk $(p<0.001)$, sweetened beverages $(p<0.001)$, and fast food $(p=.036)$, whereas British males had higher intakes of French fries/potato chips/potato chips $(p=.006)$, cake/donuts $(p<0.001)$, sweets $(p=0.008)$, and energy drinks $(p<0.001)$, than the Saudi males. For active females, the Saudis had significantly higher intakes of sweetened beverages $(p=0.017)$, sweets $(p=0.034)$, and lower energy drinks $(p=0.036)$, than British females. There also 
appeared to be a trend toward higher proportions of breakfast, vegetables, fruit and milk intakes among active adolescents in both countries compared with inactive peers.

MANCOVA results showed that gender by country interactions were present in fruit, fast food, cake/donuts and sweets intakes (all $p<0.05$, Table 2). In addition, country by activity interactions were found in sweetened beverages, French fries/potato chips and sweets consumption (all $p<0.05$, Table 2). Only fast food intake exhibited gender by activity interactions, whereas the main effect of activity was significant in breakfast, vegetables, fruit, milk, sweetened beverages and energy drinks consumption (all $p<0.05$, Table 2).

XXXXTable 2 Here XXXX

Furthermore, the results from multiple logistic regression (Table 3) analysis indicated that several dietary habits were associated with physical activity levels among Saudi and British adolescents. Being females was significantly $(p<0.001)$ associated with lower activity levels in both the Saudi and the British sample (Saudis: adjusted odds ratio $(\mathrm{aOR})=0.234 ; \mathrm{Cl}=0.181-0.302 ;$ British: $\mathrm{aOR}=0.494 ; \mathrm{Cl}=0.359-0.679)$. Furthermore, among Saudi adolescents, having lower fruit intake ( $<3$ days/week) was significantly ( $p$ $<0.001$ ) was associated with lower activity levels (aOR $=0.520 ; \mathrm{Cl}=0.380-0.712$ ), whereas increased consumption of French fries/potato chips ( $\geq 5$ days/week) was significantly $(p=0.008)$ associated with increased activity levels (aOR = 1.61; $\mathrm{Cl}=1.13-$ 2.28).

Among British adolescents, having lower intake of breakfast (less than daily) was significantly ( $p=0.045$ ) associated with lower activity levels (aOR $=0.696$; Cl= 0.489- 
0.991), whereas increased consumption of sweetened beverages (4+ days/week) was significantly ( $p=0.005)$ associated with higher activity levels $(\mathrm{aOR}=1.75 ; \mathrm{Cl}=1.18-2.61)$. Also, higher energy drinks intake (4+ days/week) was significantly $(p=0.007)$ associated with higher activity levels $(\mathrm{aOR}=2.12 ; \mathrm{Cl}=1.23-3.65)$. When sedentary behavior (total screen time) was subsequently entered as covariate, no substantial changes in the current results of the logistic regression occurred either for the Saudi or British data.

XXXXTable 3 HereXXXX

To confirm the different dietary-activity level-country associations, a posteriori analysis of variance were employed using activity level and country as fixed factors and dietary behaviors as dependent variables. In all cases significant main effects models were evident for country differences in breakfast frequency $(p=0.016)$, consumption of sugar sweetened rinks $(p=0.001)$, fruit $(p=0.001)$, fast food $(p=0.004)$, French fries $(p=$ $0.001)$, cake/donuts $(p=0.001)$ and energy drinks $(p=0.0001)$. Bonferroni post-hoc analysis indicated that youth in Saudi Arabia had higher frequency of breakfast consumption, sugar sweetened drinks and fast food compared to UK youth. Whereas UK youth had higher frequency of consumption of fruit, French fries and cakes/donuts compared to Saudi youth. Similarly, significant main effects for activity level for consumption of breakfast $(p=0.016)$, sugar sweetened drinks $(p=0.0001)$, vegetable consumption $(p=0.0001)$, fruit $(p=0.0001)$, milk $(p=0.0001)$ and energy drinks $(p=$ 0.0001). Bonferroni post-hoc analysis indicated that active youth had higher frequency of consuming breakfast, vegetables, sugar sweetened drinks, milk and energy drinks compared to inactive youth. There were no significant country by activity interactions evident using this subsequent analysis. 


\section{Discussion}

This study evidences important cross-cultural differences in the anthropometric and lifestyle habits of active and inactive adolescents from Saudi Arabia and Britain. Few studies have considered this issue, particularly in the context of dietary habits and activity levels together. This should be considered the major contribution of this study.

The results of this study support prior work which has evidenced high levels of overweight and obesity and low levels of habitual physical activity in Saudi adolescents (Al-Hazzaa, 2007; Al-Hazzaa et al., 2011c). Such findings are not surprising. Saudi Arabia has undergone rapid economic and social transformation over the past decades. Rapid urbanization, heavy reliance on automobiles and reduced occupational work demands all have contributed to lifestyle changes, including increased sedentary behaviors and reduced physical activity (Al-Hazzaa et al., 2011c, International Monetary Fund, 2012). Urbanization and related environmental determinants, including street networks engineered to discourage walking, may also have acted to deter physically active lifestyles in Saudi Arabia (Al-Hazzaa et al., 2013a). In addition, the hot and dusty environment adds another factor that discourages outdoor physical activity (Al-Hazzaa et al., 2013a). Conversely, the environment in Britain may be more conducive to outdoor physical activity and whilst the British cities used in this study are heavily urbanized, their urban design shows greater street connectivity, provision of pedestrianized areas and walkways than is the case for Saudi Arabia (International Monetary fund, 2012). This combined with different cultural norms for males and females in Saudi Arabia may also explain the gender by country differences reported here. Culturally, Saudi families may not encourage females to take part in leisure time physical activity (Al-Hazzaa et al., 2013a) which may explain some of the findings presented here, though these cultural 
norms are beginning to change but slowly. Such a conclusions is also supportive of prior research documenting socio-cultural influences on the physical activity behaviours of culturally diverse women, including Arabic speaking females living in Australia (Caperchione et al., 2011).

However, the current study develops understanding in this area by demonstrating that there are cross cultural differences in dietary habits between adolescents from Saudi Arabia and Britain and that these dietary habits also differ depending on physical activity status (inactive vs. active). Consistent with prior data from the HBSC (Vereecken et al., 2005), the present study evidences that a significant number of British and Saudi adolescents consumed few fruit and vegetables, with a high frequency of consumption of sugar-sweetened drinks. There is also known variation in food habits in adolescents from different countries (Rasmussen et al., 2006; Ng et al., 2011). The findings of the present study showed that the most active adolescents from both countries appeared generally to have healthier dietary habits than the inactive group. More specifically, the present study also evidenced that in adolescents from Saudi Arabia lower fruit intake was associated with lower activity levels but, conversely, greater consumption of French fries/potato chips was associated with being active. In British adolescents having lower intake of breakfast daily was associated with being inactive. However, being active was associated with greater consumption of sweetened beverages and energy drinks. In some ways these results might be considered contradictory, with active children having healthier dietary habits overall but poorer habits related to specific foodstuffs (e.g., energy drinks). This may be explained by the fact that sporting events and environments promote such sugary beverages and unhealthy snacks (through vending machines, commercial presences, etc...). In such cases following organized activity, youth may be more likely to consume such products. Authors have previously reported that the association between sugar- 
sweetened beverages, often marketed as sport drinks, and energy drinks, often marketed to assist in exercise or sports performance are becoming increasingly marketed to youth, particularly as a means to enhance exercise performance (Schneider and Benjamin, 2011). Such similar findings have been reported among Iranian children and adolescents (Kelishadi et al. 2007).

These results may be important and suggestive that physical activity is one of a cluster of lifestyle behaviors in adolescents and that those adolescents evidencing more positive behavior in relation to physical activity are also more likely to report more positive behaviors related to healthy eating (Dodd et al., 2010). Understanding how such dietary behaviours cluster in different countries and cultures and between adolescents who are active or inactive is a useful step in behavior modifications and establishing strategies that are country specific and amenable to change. Furthermore, as healthy dietary behaviours cluster with physical activity (Busch et al., 2013), it may be that efforts to increase habitual physical activity energy expenditure will also result in other positive behavior changes including more positive eating habits. This is because specific behavioural patterns underlie individual health behaviours (Busch et al., 2013). This suggestion is however speculative and further research, using cluster analysis or latent class analysis, is however required to understand cross cultural determinants of unhealthy dietary habits and the mechanism by which physical activity and other health related lifestyle behaviours including healthy eating cluster. Despite this, the fact that inactivity covaries with less healthy dietary habits might suggest that multimodal intervention programs would likely be more effective in achieving behavior modification than targeting a single behavior alone (Butke et al., 1997).

The present study is not without limitations. This is a cross sectional study, which does not imply causality. The self-reported nature of the data presented here can also be 
considered a limitation. Although every effort was made to minimize over- or underreporting by the participants, the limitations of assessing dietary habits and physical activity among adolescents from different countries using self-reported questionnaire must be considered when interpreting the present study findings. The dietary information obtained from the participants was based on the frequency of consumption of food items without any regard to quantity or portion size. However, portion sizes are difficult to estimate accurately, especially in people who are not used to the concept. A recent study reporting on Saudi adolescents showed that physical activity was associated with intakes of healthier dietary habits such as breakfast, vegetables, fruit and milk consumption, whereas screen time was associated with intakes of less healthier dietary habits such as fast food, cake/donuts, sugar-sweetened drinks and energy drinks consumption (AlHazzaa, et al, 2013b). However, in the present study, adding total screen time did not substantially alter the current findings. It is also possible that socio-economic status might explain some fo the variation reported in the present study. Socio-economic status was not directly measured in the present study and it is difficult to directly compare socioeconomic status across the two countries involved as there are differing metrics by which this can be assessed, specific to each country. Despite this, the sample populations were drawn from across the spectrum of socio-economic status areas/schools in the countries and regions involved and, as a consequence, it is less likely there is socio-economic bias in the data presented here. Future research should however aim to account for possible socio-economic status differences. The lack of maturational assessment is also a limitation in the present study. The sensitive nature of assessing or even reporting secondary sex characteristics in Saudi Arabia make it difficult to complete such assessments. Every effort was also made to ensure that the participants were fairly representative of major cities in each of the respective countries involved; it is difficult to 
generalize the study results to all adolescents living in large cities, especially in UK. Most major cities in Saudi Arabia with the exception of those in Southwestern Mountains have fairly similar landscapes and environmental determinants of physical activity and dietary habits. However, not all British cities have the same provisions for promoting physical activity and dietary habits. UK cities would also vary considerably in terms of walkability, housing density, street intersection density, land use mix, green space and traffic volume. In the current study, the cities of Birmingham and Coventry were employed as sites for data collection. These cities are largely industrial and multicultural cities where a large range of energy dense and culturally varied foodstuffs are readily available. Employing assessment of the built environment in cross-cultural research of this nature would be useful in understanding how built environment differences might impact lifestyle behaviors in youth. Unfortunately comparable measures of the built environment for Britain and Saudi Arabia were not available in the present study. Among the strengths of the current research are the use of highly standardized protocols and procedures in all of the participating centers. In addition, the physical activity questionnaire used in this survey was found to be reproducible, valid and comprehensive, utilizing all domains of physical activity. The present study identifies cross-cultural differences and similarities in lifestyle habits in adolescents from Britain and Saudi Arabia.

\section{Acknowledgments}

Professor Hazzaa M. Al-Hazzaa's research was supported by a fund from the Deanship of Scientific Research at King Saud University, through research group number RGPVPP-307. Additional support was provided by the Educational Research Center, College of Education, King Saud University. Professor Yahya Al-Nakeeb was supported by the 
Research Committee of Newman University College. The authors also acknowledge the assistance of numerous male and female research assistants who kindly helped in the data collection at the participating cities.

\section{References}

Ainsworth BE, Haskell WL, Herrmann SD, Meckes N, Bassett DR Jr, Tudor-Locke C, et al. 2011. Compendium of physical activities: A second update of codes and MET values. Med Sci Sports Exerc 43: 1575-1581.

Al-Hazzaa HM. 2007. Rising trends in BMI of Saudi adolescents: evidence from three national cross sectional studies. Asia Pac J Clin Nutr 16: 462-466.

Al-Hazzaa HM, Al-Ahmadi M. 2003. A Self-reported questionnaire for the assessment of physical activity in youth 15-25 years: Development, reliability and construct validity. Arab J of Food \& Nutrition 4: 279-291.

Al-Hazzaa HM, Al-Nkaeeb Y, Duncan, MJ, Al-Sobayel HI, Abahussain NA, Musaiger AO, Lyons M, Collins P, Nevill A. 2013a. A cross-cultural comparison of health behaviors between Saudi and British adolescents living in Urban Areas: gender by Country Analysis. Int J Environ Res Public Health 10: 6701-6720.

Al-Hazzaa HM, Al-Sobayel H, Abahussain N, Qahwaji D, Alahmadi MA, Musaiger AO. 2013b. Association of dietary habits with physical activity and screen 
time among adolescents living in Saudi Arabia. J Hum Nutr Diet e-pub ahead of print (doi: 10.1111/jhn.12147.).

Al-Hazzaa HM, Musaiger A; ATLS Group. 2011a. Arab Teens Lifestyle Study (ATLS): objectives, design, methodology and implications. Diabetes Metab Syndr Obes 4: 417-426.

Al-Hazzaa, HM, Al-Sobayel, HI, Musaiger, AO. 2011b. Convergent validity of the Arab Teens Lifestyle Study (ATLS) physical activity questionnaire. Int J Environ Res Public Health 8: 3810-3820.

Al-Hazzaa HM, Abahussain N, Al-Sobayel H, Qahwaji D, Musaiger AO. 2011c. Physical activity, sedentary behaviors and dietary habits among Saudi adolescents relative to age, gender and region. Int J Behav Nutr Phys Act 8:140.

Al-Nakeeb Y, Lyons M, Collins P, Al-Nuaim A, Al-Hazzaa H, Duncan MJ, Nevill A. 2012. Obesity, physical activity and sedentary behavior amongst British and Saudi youth: a cross-cultural study. Int J Environ Res Public Health 9: 1490-1506.

American Academy of Pediatrics: Committee on Public Education. 2001. Children, adolescents, and television. Pediatrics 107: 423-426.

Beardsley, LM, Pendersen P. 1997. Health and culture-centred intervention. In: Berry JW, Segall M, Kagitcibasi C, editors. Handbook of cross cultural 
psychology: Social behavior and Application. Boston: Ally and Bacon. Pp413-448.

Burke V, Milligam RA, Beilin LJ, Dunbar D, Spencer M, Balde E, Gracey MP. 1997. Clustering of health-related behaviors among 18-year old Australians. Prev Med 26: 724-733.

Busch V, Van Stel HF, Schrijvers AJ, de Leeuw JR. 2013. Clustering of healthrelated behaviours, health outcomes and demographics in Dutch adolescents: a cross-secitonal study. BMC Pub HIth 13: 1118.

Caperchione CM, Kolt GS, Tennent R, Mummery WK. 2013. Physical activity behaviours of Culturally and Linguistically Diverse (CALD) women living in Australia: A qualitative study of socio-cultural influences. BMC Pub HIth 11: 26.

Chen MY, James K, Wang EK. 2007. Comparison of health-promoting behavior between Taiwanese and American adolescents: a cross-sectional questionnaire survey. Int J Nurs Stud 44: 59-69.

Cole T, Bellizzi M, Flegal K, Dietz W. 2000. Establishing a standard definition of child overweight and obesity worldwide: International survey. BMJ 320: $1240-1243$.

Dodd L, Al-Nakeeb Y, Nevill A, Forshaw M. 2010. Lifestyle risk factors of students: A cluster analytical approach. Prev Med 51: 73-77. 
Duncan MJ, Birch S, Al-Nakeeb Y, Nevill AM. 2012. Ambulatory physical activity levels of white and South Asian children in Central England. Acta Paediatr 101: e156-162.

Ekelund U, Brage S, Froberg K, Harro M, Anderssen SA, Sardinha LB, Riddoch C, Andersen LB. 2006. TV viewing and physical activity are independently associated with metabolic risk in children: The European Youth Heart Study. PLoS Med 3: e488.

International Monetary Fund. World Economic Outlook Database-October 2012. http://www.imf.org/external/pubs/ft/weo/2012/02/weodata/index.aspx. Accessed on 19/12/2013.

Kelishadi R, Ardalan G, Gheiratmand R, Gouya MM, Razaghi EM, Delavari A, Majdzadeh R, Heshmat R, Motaghian M, Barekati H, Mahmoud-Arabi MS, Riazi MM; CASPIAN Study Group.2007. Association of physical activity and dietary behaviours in relation to the body mass index in a national sample of Iranian children and adolescents: CASPIAN Study. Bull World Health Organ. 85:19-26.

Mitchell JA, Pate RR, Dowda M, Mattocks C, Riddoch C, Ness AR, Blair SN. 2012. A prospective study of sedentary behavior in a large cohort of youth. Med Sci Sports Exerc 44: 1081-1087.

Ng SW, Zaghloul S, Ali H, Harrison G, Yeatts K, El Sadig M, Popkin BM. 2011. Nutrition transition in the United Arab Emirates. Eur J Clin Nutr 65: 13281337. 
Nilsson, A., Anderssen, SA, Andersen LB, Froberg K, Riddoch C, Sardinha LB, Ekelund U. 2009. Between- and within day variability in physical activity and inactivity in 9 and 15 year old European children. Scand J Med Sci Sports 19: 10-18.

Rasmussen M, Krølner R, Klepp KI, Lytle L, Brug J, Bere E, Due P. 2006. Determinants of fruit and vegetable consumption among children and adolescents: a review of the literature. Part I: Quantitative studies. Int J Behav Nutr Phys Act 3: 22.

Riddoch C, Edwards D, Page A, Froberg K, Anderssen SA, et al. 2005. The European Youth Heart Study - Cardiovascular disease risk factors in children: Rationale, aims, study design, and validation of methods. J. Phys. Act. Health 2, 115-129.

Ridley K, Ainsworth B, Olds T. 2008. Development of a compendium of energy expenditure for youth. Int J Behav Nutr Phys Act 5: 45.

Rogers A, Adamson JE, McCarthy M. 1997. Variations in health behaviours among inner city 12-year-olds from four ethnic groups. Ethn Health 2: 309316.

Sardinha LB, Andersen LB, Anderssen SA, Quiterio AL, Ornelas R, Froberg K, et al. 2008. Objectively measured time spent sedentary is associated with insulin resistance independent of overall and central body fat in 9-to 10-year-old Portuguese children. Diabetes Care 31: 569-575. 
Schneider MB, Benjamin HJ. 2011. Sports drinks and energy drinks for children and adolescents: Are they appropriate? Pediatrics 127: 1182-1189.

Shaw NJ, Crabtree NJ, Kibirige MS, Fordham JN. 2007. Ethnic and gender differences in body fat in British schoolchildren as measured by DXA. Arch Dis Child 92: 872-875.

Sluyter JD, Schaaf D, Metcalf PA, Scragg RK. 2010. Dietary intakes of Pacific, Māori, Asian and European adolescents: the Auckland High School Heart Survey. Aust N Z J Public Health 34: 32-37.

Telama R. 2009. Tracking of physical activity from childhood to adulthood: a review. Obes Facts 2: 187-195.

Troiano RP, Berrigan D, Dodd KW, Masse LC, Tilert T, McDowell M. 2008. Physical activity in the United States measured by accelerometer. Med Sci Sports Exerc 40: 181-188.

Vereecken CA, De Henauw S, Maes L. 2005. Adolescents' food habits: results of the Health Behaviour in School-aged Children survey. Br J Nutr 94: 423431.

Wedderkopp N, Froberg K, Steen Hansen H, Riddoch C, Bo Andersen L. 2003. Cardiovascular risk factors cluster in children and adolescents with low physical fitness: The European Youth Heart Study (EYHS). Ped Exerc Sci 15: $419-427$.

World Health Organization. 2004. Global Strategy on Diet, Physical Activity and Health. WHA57.17. Geneva, Switzerland: WHO. 
Table 1. Descriptive characteristics of Saudi and British adolescents relative to gender and levels of activity $(N=2799)$.

\begin{tabular}{|c|c|c|c|c|c|c|c|c|c|}
\hline \multirow[t]{3}{*}{ Variable } & \multicolumn{4}{|c|}{ Male } & \multicolumn{4}{|c|}{ Female } & \multirow[t]{3}{*}{$p$-value * } \\
\hline & \multicolumn{2}{|c|}{ Active } & \multicolumn{2}{|c|}{ Inactive } & \multicolumn{2}{|c|}{ Active } & \multicolumn{2}{|c|}{ Inactive } & \\
\hline & Saudi & British & Saudi & British & Saudi & British & Saudi & British & \\
\hline $\begin{array}{l}\text { Number of } \\
\text { participants }\end{array}$ & 426 & 483 & 371 & 102 & 168 & 374 & 683 & 192 & \\
\hline Age (year) ${ }^{a}$ & $\begin{array}{l}16.5 \\
\pm 1.0\end{array}$ & $\begin{array}{l}15.2 \\
\pm 0.98\end{array}$ & $\begin{array}{c}16.6 \\
\pm 0.98\end{array}$ & $\begin{array}{l}15.2 \\
\pm 0.88\end{array}$ & $\begin{array}{l}16.4 \\
\pm .93\end{array}$ & $\begin{array}{l}15.2 \\
\pm 0.94\end{array}$ & $\begin{array}{l}16.5 \\
\pm 0.95\end{array}$ & $\begin{array}{l}15.2 \\
\pm 0.95\end{array}$ & $\begin{array}{l}\text { Country: } 0.008 \\
\text { The rest NS }\end{array}$ \\
\hline Weight $(\mathrm{kg})^{\mathbf{b}}$ & $\begin{array}{c}68.2 \\
\pm 19.4\end{array}$ & $\begin{array}{c}64.4 \\
\pm 12.9\end{array}$ & $\begin{array}{l}69.8 \\
\pm 20.8\end{array}$ & $\begin{array}{c}64.7 \\
\pm 15.3\end{array}$ & $\begin{array}{r}60.7 \\
\pm 17.1\end{array}$ & $\begin{array}{l}58.9 \\
\pm 11.2\end{array}$ & $\begin{array}{l}57.7 \\
\pm 14.6\end{array}$ & $\begin{array}{c}57.6 \\
\pm 12.2\end{array}$ & $\begin{array}{l}\text { Gender: }<0.000 \\
\text { Gender } x \text { country:0.040 } \\
\text { Gender } x \text { activity: } 0.046 \\
\text { The rest NS }\end{array}$ \\
\hline Height $(\mathrm{cm})^{\mathbf{b}}$ & $\begin{array}{c}168.3 \\
\pm 7.7\end{array}$ & $\begin{array}{c}171.8 \\
\pm 8.0\end{array}$ & $\begin{array}{c}168.4 \\
\pm 7.5\end{array}$ & $\begin{array}{c}170.4 \\
\pm 9.3\end{array}$ & $\begin{array}{c}157.3 \\
\pm 6.1\end{array}$ & $\begin{array}{c}162.2 \\
\pm 7.3\end{array}$ & $\begin{array}{c}157.1 \\
\pm 5.9\end{array}$ & $\begin{array}{c}162.1 \\
\pm 8.5\end{array}$ & $\begin{array}{l}\text { Gender: }<0.000 \\
\text { Country: }<0.000 \\
\text { Gender } x \text { country:0.007 } \\
\text { The rest NS }\end{array}$ \\
\hline $\operatorname{BMI}\left(\mathrm{kg} / \mathrm{m}^{2}\right)^{b}$ & $\begin{array}{l}23.9 \\
\pm 6.3\end{array}$ & $\begin{array}{l}21.7 \\
\pm 3.6\end{array}$ & $\begin{array}{l}24.5 \\
\pm 6.9\end{array}$ & $\begin{array}{l}22.2 \\
\pm 4.7\end{array}$ & $\begin{array}{r}24.5 \\
\pm 6.6\end{array}$ & $\begin{array}{l}22.4 \\
\pm 4.0\end{array}$ & $\begin{array}{l}23.4 \\
\pm 5.6\end{array}$ & $\begin{array}{l}21.9 \\
\pm 4.1\end{array}$ & $\begin{array}{l}\text { Country: }<0.000 \\
\text { Gender } x \text { activity: } 0.014 \\
\text { The rest NS }\end{array}$ \\
\hline $\begin{array}{l}\text { Waist } \\
\text { circumference } \\
(\mathrm{cm})^{\mathbf{b}}\end{array}$ & $\begin{array}{c}78.7 \\
\pm 15.3\end{array}$ & $\begin{array}{l}77.1 \\
\pm 9.8\end{array}$ & $\begin{array}{c}79.6 \\
\pm 16.2\end{array}$ & $\begin{array}{c}78.8 \\
\pm 10.9\end{array}$ & $\begin{array}{r}74.5 \\
\pm 13.6\end{array}$ & $\begin{array}{c}75.5 \\
\pm 10.2\end{array}$ & $\begin{array}{l}72.6 \\
\pm 12.7\end{array}$ & $\begin{array}{l}76.9 \\
\pm 10.1\end{array}$ & $\begin{array}{l}\text { Gender: }<0.000 \\
\text { Country: }<0.000 \\
\text { Gender } x \text { country:0.003 } \\
\text { The rest NS }\end{array}$ \\
\hline WHtR (\%) & $\begin{array}{l}46.7 \\
\pm 8.7\end{array}$ & $\begin{array}{l}44.9 \\
\pm 5.3\end{array}$ & $\begin{array}{l}47.2 \\
\pm 9.4\end{array}$ & $\begin{array}{l}46.2 \\
\pm 5.8\end{array}$ & $\begin{array}{l}47.4 \\
\pm 8.5\end{array}$ & $\begin{array}{l}46.6 \\
\pm 6.5\end{array}$ & $\begin{array}{l}46.2 \\
\pm 8.0\end{array}$ & $\begin{array}{l}47.5 \\
\pm 6.0\end{array}$ & $\begin{array}{l}\text { Gender } x \text { country: } 0.025 \\
\text { The rest NS }\end{array}$ \\
\hline $\begin{array}{l}\text { Total MET-min. } \\
\text { per week }^{\mathbf{b}}\end{array}$ & $\begin{array}{c}4809.8 \\
\pm 2733.0\end{array}$ & $\begin{array}{c}5542.9 \\
\pm 2648.5\end{array}$ & $\begin{array}{l}752.5 \\
\pm 473.4\end{array}$ & $\begin{array}{l}997.2 \\
\pm 483.9\end{array}$ & $\begin{array}{c}3191.0 \\
\pm 1598.3\end{array}$ & $\begin{array}{c}3723.7 \\
\pm 1903.4\end{array}$ & $\begin{array}{l}580.5 \\
\pm 425.0\end{array}$ & $\begin{array}{l}1003.1 \\
\pm 432.3\end{array}$ & $\begin{array}{l}\text { Gender: }<0.000 \\
\text { Country: }<0.000 \\
\text { Activity: }<0.000 \\
\text { Gender } x \text { activity: }<0.000 \\
\text { The rest NS }\end{array}$ \\
\hline
\end{tabular}

Data are means and standard deviations.

$\mathrm{BMI}=$ body mass index; NS = Not significant.

a Three-way ANOVA tests (gender by country by activity).

b Three-way MANCOVA tests of between subjects effects, controlling for the effect of age. 
Table 2. Cross tabulation (\%) and mean (SD) of eating habits of Saudi and British adolescents relative to gender and levels of activity.

\begin{tabular}{|c|c|c|c|c|c|c|c|c|c|}
\hline \multirow[t]{2}{*}{ Variable } & \multicolumn{4}{|c|}{ Male } & \multicolumn{4}{|c|}{ Female } & \multirow[t]{2}{*}{ Chi-Square tests } \\
\hline & Saudi & British & Saudi & British & Saudi & British & Saudi & British & \\
\hline \multicolumn{10}{|l|}{ Breakfast intake: } \\
\hline Daily & 37.6 & 41.5 & 30.7 & 28.9 & 28.7 & 30.2 & 21.3 & 21.5 & $\begin{array}{l}\text { Male active: } 0.128 \\
\text { Male inactive: } 0.411 \\
\text { Female active: } 0.408 \\
\text { Female inactive: } 0.520\end{array}$ \\
\hline \multicolumn{10}{|l|}{ Vegetables intake: } \\
\hline Daily & 29.5 & 20.0 & 16.0 & 12.5 & 31.0 & 25.1 & 20.7 & 22.6 & \multirow{3}{*}{$\begin{array}{l}\text { Male active: } 0.001 \\
\text { Male inactive: } 0.250 \\
\text { Female active: } 0.094 \\
\text { Female inactive:0.312 }\end{array}$} \\
\hline Less than daily & 70.5 & 80.0 & 84.0 & 87.5 & 69.0 & 74.9 & 79.3 & 77.4 & \\
\hline Mean $(S D)^{\star} \mathbf{b}, \mathbf{d}$ & $\begin{array}{c}4.1 \\
(2.4)\end{array}$ & $\begin{array}{c}4.0 \\
(2.2)\end{array}$ & $\begin{array}{c}3.2 \\
(2.3)\end{array}$ & $\begin{array}{c}3.3 \\
(2.2)\end{array}$ & $\begin{array}{c}4.1 \\
(2.3)\end{array}$ & $\begin{array}{c}4.2 \\
(2.2)\end{array}$ & $\begin{array}{c}3.6 \\
(2.3)\end{array}$ & $\begin{array}{c}3.9 \\
(2.2)\end{array}$ & \\
\hline Less than daily & 78.8 & 82.7 & 88.6 & 91.8 & 82.1 & 78.6 & 92.1 & 90.5 & \multirow{2}{*}{$\begin{array}{l}\text { Male inactive: } 0.246 \\
\text { Female active: } 0.203 \\
\text { Female inactive: } 0.279\end{array}$} \\
\hline Mean $(S D)^{\star} \mathbf{d}, \mathbf{g}$ & $\begin{array}{c}3.7 \\
(2.3)\end{array}$ & $\begin{array}{c}3.7 \\
(2.2)\end{array}$ & $\begin{array}{c}2.8 \\
(2.2)\end{array}$ & $\begin{array}{c}2.6 \\
(2.1)\end{array}$ & $\begin{array}{c}3.2 \\
(2.3)\end{array}$ & $\begin{array}{c}3.8 \\
(2.2)\end{array}$ & $\begin{array}{l}2.3 \\
(2.0)\end{array}$ & $\begin{array}{c}3.0 \\
(2.1)\end{array}$ & \\
\hline \multicolumn{10}{|l|}{ Milk intake: } \\
\hline Daily & 32.3 & 27.0 & 26.9 & 26.5 & 42.7 & 31.5 & 27.1 & 25.8 & \multirow{3}{*}{$\begin{array}{l}\text { Male active: }<0.001 \\
\text { Male inactive: } 0.451 \\
\text { Female active: } 0.120 \\
\text { Female inactive:0.497 }\end{array}$} \\
\hline Less than daily & 67.7 & 73.0 & 73.1 & 73.5 & 57.3 & 68.5 & 72.9 & 74.2 & \\
\hline Mean $(S D)^{\star} \mathbf{b}, \mathbf{d}$ & $\begin{array}{c}4.8 \\
(2.3)\end{array}$ & $\begin{array}{c}4.6 \\
(2.1)\end{array}$ & $\begin{array}{c}4.1 \\
(2.4)\end{array}$ & $\begin{array}{c}4.3 \\
(2.0)\end{array}$ & $\begin{array}{c}4.1 \\
(2.6)\end{array}$ & $\begin{array}{c}4.4 \\
(2.1)\end{array}$ & $\begin{array}{l}3.8 \\
(2.5)\end{array}$ & $\begin{array}{c}4.1 \\
(2.2)\end{array}$ & \\
\hline \multicolumn{10}{|l|}{$\begin{array}{l}\text { Sweetened beverages } \\
\text { intake: }\end{array}$} \\
\hline$<4$ days/week & 69.0 & 74.6 & 71.2 & 82.3 & 76.0 & 77.1 & 75.6 & 73.5 & \multirow{2}{*}{$\begin{array}{l}\text { Male active: } 0.036 \\
\text { Male inactive: } 0.017 \\
\text { Female active: } 0.313 \\
\text { Female inactive:0.436 }\end{array}$} \\
\hline Mean $(S D) \star \mathbf{e}, \mathbf{g}$ & $\begin{array}{c}3.0 \\
(2.0)\end{array}$ & $\begin{array}{c}2.7 \\
(1.9)\end{array}$ & $\begin{array}{c}2.8 \\
(2.0)\end{array}$ & $\begin{array}{c}2.2 \\
(1.7)\end{array}$ & $\begin{array}{c}2.7 \\
(1.9)\end{array}$ & $\begin{array}{c}2.5 \\
(1.8)\end{array}$ & $\begin{array}{c}2.6 \\
(1.8)\end{array}$ & $\begin{array}{c}2.6 \\
(1.8)\end{array}$ & \\
\hline \multicolumn{10}{|l|}{$\begin{array}{l}\text { French fries/potato } \\
\text { chips intake: }\end{array}$} \\
\hline $4+$ days/week & 26.5 & 34.5 & 19.8 & 34.7 & 37.5 & 35.7 & 30.2 & 35.1 & \multirow{3}{*}{$\begin{array}{l}\text { Male active: } 0.006 \\
\text { Male inactive: } 0.002 \\
\text { Female active: } 0.377 \\
\text { Female inactive:0.118 }\end{array}$} \\
\hline$<4$ days/week & 73.5 & 65.5 & 80.2 & 65.3 & 62.5 & 64.3 & 69.8 & 64.9 & \\
\hline Mean $(S D)^{\star} \mathbf{b}, \mathbf{c}, \mathbf{f}$ & $\begin{array}{c}2.6 \\
(2.1)\end{array}$ & $\begin{array}{c}3.0 \\
(1.9)\end{array}$ & $\begin{array}{c}2.1 \\
(1.8)\end{array}$ & $\begin{array}{c}3.2 \\
(1.9)\end{array}$ & $\begin{array}{c}3.2 \\
(2.1)\end{array}$ & $\begin{array}{c}2.9 \\
(2.0)\end{array}$ & $\begin{array}{c}2.8 \\
(2.0)\end{array}$ & $\begin{array}{c}2,9 \\
(1.9)\end{array}$ & \\
\hline \multicolumn{10}{|l|}{ Cake/donut intake: } \\
\hline 4+ days/week & 28.9 & 39.7 & 23.4 & 38.0 & 35.7 & 39.6 & 27.7 & 45.0 & \multirow{3}{*}{$\begin{array}{l}\text { Male active: }<0.001 \\
\text { Male inactive: } 0.003 \\
\text { Female active: } 0.221 \\
\text { Female inactive: }<0.001\end{array}$} \\
\hline$<4$ days/week & 71.1 & 60.3 & 76.6 & 62.0 & 64.3 & 60.4 & 72.3 & 55.0 & \\
\hline $\operatorname{Mean}(\mathrm{SD})^{\star} \mathbf{b}, \mathbf{c}, \mathbf{g}$ & $\begin{array}{c}2.6 \\
(2.1)\end{array}$ & $\begin{array}{c}3.1 \\
(2.0)\end{array}$ & $\begin{array}{c}2.4 \\
(2.0)\end{array}$ & $\begin{array}{c}3.1 \\
(2.2)\end{array}$ & $\begin{array}{c}3.0 \\
(2.1)\end{array}$ & $\begin{array}{c}3.2 \\
(2.0)\end{array}$ & $\begin{array}{c}2.7 \\
(2.0)\end{array}$ & $\begin{array}{c}3.5 \\
(2.1)\end{array}$ & \\
\hline
\end{tabular}




\begin{tabular}{cccccccccl} 
Sweets intake: & & & & & & & & & \\
4+ days/week & 38.8 & 47.0 & 33.9 & 40.8 & 60.7 & 51.9 & 53.0 & 59.3 & Male active: 0.008 \\
< 4 days/week & 61.2 & 53.0 & 66.1 & 59.2 & 39.3 & 48.1 & 47.0 & 40.7 & Male inactive: 0.124 \\
Mean (SD)* b, f, $\mathbf{g}$ & 3.2 & 3.6 & 2.9 & 3.6 & 4.3 & 3.8 & 4.0 & 4.0 & Female active: 0.034 \\
& $(2.3)$ & $(2.1)$ & $(2.2)$ & $(2.1)$ & $(2.3)$ & $(2.0)$ & $(2.3$ & $(2.1)$ & Female inactive:0.076 \\
& & & & & & & & & \\
Energy drinks intake: & & & & & & & \\
4+ days/week & 16.5 & 28.9 & 14.6 & 21.0 & 12.0 & 18.5 & 8.3 & 9.5 & Male active: 0.001 \\
< 4 days/week & 83.5 & 71.1 & 85.4 & 79.0 & 88.0 & 81.5 & 91.7 & 90.5 & Male inactive: 0.085 \\
Mean (SD)* b, c, d & 1.6 & 2.3 & 1.4 & 1.7 & 1.1 & 1.6 & 0.84 & 1.1 & Female active: 0.036 \\
& $(2.2)$ & $(2.2)$ & $(2.0)$ & $(2.2)$ & $(1.9)$ & $(2.1)$ & $(1.6)$ & $(1.7)$ & \\
\hline
\end{tabular}

Data are percentages or means and SD.

* Three-way MANCOVA tests, controlling for the effect of age: $a=$ significant differences at $p$ $<.05$ for the effect of age; $\mathrm{b}=$ significant differences at $p<.05$ for the effect of gender; $\mathrm{c}=$ significant differences at $p<.05$ for the effect of country; $d=$ significant differences at $p<.05$ for the effect of activity level; e = significant differences at $p<.05$ for the interaction effect of gender by activity; $f=$ significant differences at $p<.05$ for the interaction effect of country by activity; $g=$ significant differences at $p<.05$ for the interaction effect of gender by country. 
Table 3. Logistic regression analyses, adjusted for age, gender, and overweight/obesity status for selected eating habits relative to activity levels (active versus inactive) among Saudi and British adolescents.

\begin{tabular}{|c|c|c|c|c|c|c|}
\hline \multirow{2}{*}{ Variable } & \multicolumn{3}{|c|}{ Saudi adolescents } & \multicolumn{3}{|c|}{ British adolescents } \\
\hline & $\mathrm{aOR}$ & $(95 \% \mathrm{CI})$ & $p$ & $\mathrm{aOR}$ & $(95 \% \mathrm{CI})$ & $p$ \\
\hline Age & 0.933 & $0.830-1.05$ & 0.242 & 0.913 & $0.781-1.07$ & 0.251 \\
\hline Gender (female versus male) & 0.234 & $0.181-0.302$ & $<0.001$ & 0.494 & $0.359-0.679$ & $<0.001$ \\
\hline $\begin{array}{l}\text { Non-overweight/non- obese vs } \\
\text { Overweigh/obese }\end{array}$ & 1.143 & $0.902-1.45$ & 0.267 & 0.898 & $0.633-1.28$ & 0.549 \\
\hline $\begin{array}{l}\text { Breakfast intake: } \\
\qquad \leq 5 \text { days/week (ref) }\end{array}$ & 1.00 & & - & 1.00 & & - \\
\hline 3-4 days/week & 0.952 & $0.657-1.38$ & 0.796 & 0.803 & $0.585-1.54$ & 0.830 \\
\hline$<3$ days/week & 0.850 & $0.652-1.11$ & 0.227 & 0.696 & $0.489-0.991$ & 0.045 \\
\hline $\begin{array}{l}\text { Vegetables intake: } \\
\quad \geq 5 \text { days/week (ref) }\end{array}$ & 1.00 & & - & 1.00 & & - \\
\hline 3-4 days/week & 0.846 & $0.623-1.15$ & 0.284 & 1.05 & $0.710-1.56$ & 0.798 \\
\hline$<3$ days/week & 0.778 & $0.572-1.06$ & 0.110 & 0.836 & $0.540-1.29$ & 0.419 \\
\hline Fruits intake: $\geq 5$ days/week (ref) & 1.00 & & - & 1.00 & & - \\
\hline 3-4 days/week & 0.772 & $0.554-1.08$ & 0.125 & 0.942 & $0.616-1.44$ & 0.785 \\
\hline$<3$ days/week & 0.520 & $0.380-0.712$ & $<0.001$ & 0.490 & $0.323-0.743$ & 0.001 \\
\hline Milk intake: $\geq 5$ days/week (ref) & 1.00 & & - & 1.00 & & - \\
\hline 3-4 days/week & 1.01 & $0.739-1.37$ & 0.963 & 1.03 & $0.673-1.57$ & 0.893 \\
\hline$<3$ days/week & 0.765 & $0.568-1.03$ & 0.077 & 0.927 & $0.642-1.34$ & 0.687 \\
\hline $\begin{array}{l}\text { Sugar-sweetened drink: } \\
<3 \text { days/week (ref) }\end{array}$ & 1.00 & & - & 1.00 & & - \\
\hline 3-4 days/week & 1.07 & $0.775-1.48$ & 0.684 & 1.23 & $0.848-1.79$ & 0.274 \\
\hline$\geq 5$ days/week & 1.15 & $0.797-1.64$ & 0.464 & 1.75 & $1.18-2.61$ & 0.005 \\
\hline $\begin{array}{l}\text { Fast food: } \\
\qquad<3 \text { days/week (ref) }\end{array}$ & 1.00 & & - & 1.00 & & - \\
\hline 3-4 days/week & 1.05 & $0.786-1.40$ & 0.741 & 0.963 & $0.666-1.39$ & 0.840 \\
\hline$\geq 5$ days/week & 0.964 & $0.676-1.38$ & 0.840 & 1.39 & $0.852-2.28$ & 0.186 \\
\hline $\begin{array}{l}\text { French fries/potato chips: } \\
<3 \text { days/week (ref) }\end{array}$ & 1.00 & & - & 1.00 & & - \\
\hline 3-4 days/week & 1.05 & $0.778-1.42$ & 0.741 & 0.799 & $0.555-1.15$ & 0.228 \\
\hline$\geq 5$ days/week & 1.61 & $1.13-2.28$ & 0.008 & 0.995 & $0.634-1.56$ & 0.982 \\
\hline Cake/donuts: < 3 days/week (ref) & 1.00 & & - & 1.00 & & - \\
\hline 3-4 days/week & 0.834 & $0.610-1.14$ & 0.982 & 1.05 & $0.713-1.55$ & 0.797 \\
\hline$\geq 5$ days/week & 1.02 & $0.732-1.42$ & 0.982 & 0.678 & $0.413-1.06$ & 0.090 \\
\hline Sweets/candy: < 3 days/week (ref) & 1.00 & & - & 1.00 & & - \\
\hline 3-4 days/week & 0.944 & $0.691-1.29$ & 0.719 & 1.06 & $0.709-1.59$ & 0.772 \\
\hline
\end{tabular}




\begin{tabular}{ccccccc}
$\geq 5$ days/week & 1.13 & $0.826-1.55$ & 0.446 & 0.669 & $0.428-1.05$ & 0.078 \\
Energy drinks: $<3$ days/week (ref) & 1.00 & & - & 1.00 & & - \\
3-4 days/week & 1.23 & $0.820-1.85$ & 0.315 & 1.23 & $0.771-1.96$ & 0.982 \\
$\geq$ 5 days/week & 1.48 & $0.948-2.30$ & 0.085 & 2.12 & $1.23-3.65$ & $\mathbf{0 . 0 0 7}$ \\
\hline
\end{tabular}

aOR = adjusted odds ratio; $\mathrm{Cl}=$ confidence interval; ref $=$ reference category. Please note, unhealthy dietary habits (sugar-sweetened drinks, fast food, French fries/potato chips, cake/donuts, sweets/candy and energy drinks) were reversed when reported in the logistic regression. In such cases an increased aOR is associated with increased physical activity. 